\title{
Medical Education Research and the Hierarchy in Medical Training: An Interview with Dr. Dylan Bould
}

\author{
Menachem Benzaquen, $\mathrm{BSc}^{1}$
}

${ }^{1}$ Faculty of Medicine, University of Ottawa

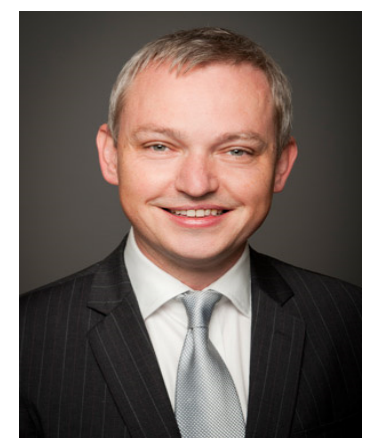

A B STRACT

Dr. Dylan Bould is an anesthesiologist at CHEO (Children's Hospital of Eastern Ontario) and Director of Education Research at the University of Ottawa's Department of Anesthesiology. Dr. Bould began training in anesthesia in the U.K. and completed fellowships in pediatric anesthesia and medical education at SickKids and St. Michael's Hospital in Toronto, as well as a pediatric cardiac anesthesia fellowship in London, England. Over the course of his fellowships in Toronto, Dr. Bould completed a Master of Education at the University of Toronto focusing on medical education. Dr. Bould is also involved in global health, having worked in Nepal and Kenya, and was part of the organization process of the University of Zambia Anesthesia Residency Program. Dr. Bould's current research focuses on hierarchy in medical training, mentorship in medical education, and simulation in healthcare education.

\section{RÉ S U MÉ}

Dr Dylan Bould est un anesthésiologiste au Centre hospitalier pour enfants de l'est de l'Ontario (CHEO) et le directeur de la recherche en enseignement au département d'anesthésie de l'Université d'Ottawa. Dr Bould a commencé sa formation en anesthésie au Royaume-Uni et a complété des formations complémentaires (fellowships) en anesthésie pédiatrique et en enseignement médical à SickKids et à l'Hôpital St Michael à Toronto, ainsi qu'une formation en anesthésie cardiaque pédiatrique à Londres, en Angleterre. Au cours de ses formations complémentaires à Toronto, Dr Bould a complété une maîtrise en éducation à l'Université de Toronto axée sur l'enseignement médical. Dr Bould est également impliqué dans le domaine de la santé mondiale, ayant travaillé au Népal et au Kenya, et ayant aidé à mettre sur pied le programme de résidence en anesthésie à l'Université de la Zambie. La recherche actuelle de Dr Bould se concentre sur la hiérarchie présente lors de la formation médicale, le mentorat en enseignement médical, et la simulation dans l'enseignement des soins de santé.

\section{DR. BOULD, THANK YOU SO MUCH FOR TAKING THE TIME FOR THIS INTERVIEW. CAN YOU TELL US A BIT ABOUT YOUR BACKGROUND IN ANESTHESIA AND EDUCATION RESEARCH? CAN YOU ALSO TELL US ABOUT WHAT BROUGHT YOU TO EDUCATION RESEARCH?}

It was in London in the U.K. where I did my anesthesia training. I then came to Toronto where I did fellowships in medical education and simulation at St. Michael's and completed a Master of Education at the University of Toronto at the same time. I also did a pediatric anesthesia fellowship in Toronto and a pediatric cardiac anesthesia fellowship back in London. I have been here in Ottawa for the past six years working at CHEO.

The education research actually came about from my time at St. Michael's where education research was a really big part of the fellowship. I had the privilege of having some very good mentorship from Viren Naik, who is currently here at The Ottawa HospiKeywords: Medical Education Research; Hierarchy in Medicine; Mentorship tal, and that is what really got me started along that path. To be honest with you, I did the fellowship at St. Michael's to become a better educator, and I wanted to learn more about teaching and simulation education. I was keen to get involved in research because I felt everybody should be involved in learning about the research process. Research also opens doors in terms of where one can work in the future. When I actually started doing the research in my fellowship, I began to enjoy education research more than anything else. I really enjoyed reading about the area you are interested in and investigating a specific issue that you want to address. It is a very different mindset than what you typically do in anesthesia, which is very much episodic when you go into the operating room and deal with one patient at a time. I think it is a great balance with the clinical work, so I got involved in many projects, made many connections within Canada, and made it a major focus of my career. 
I UNDERSTAND THE YOU PUBLISHED A STUDY ABOUT THE PRESSURE MEDICAL TRAINEES FACE TO COMPLY WITH STAFF PHYSICIANS AND HOW PATIENT SAFETY IS SOMETIMES COMPROMISED IN SUCH SCENARIOS. CAN YOU DESCRBIE THIS STUDY AND WHAT YOU FOUND?

We have published a few studies along this general line of research $[1,2]$. There have been quantitative studies using a simulated clinical environment where the behavior of the trainees was recorded and analyzed by a group of experts using validated tools to look at behavioral differences. We have also done qualitative research where we ask people questions during interviews, and we try to learn why people behave the way they do. We also look at how clinical simulations compare to the wards, emergency department and operating room. What we have discovered is that a hierarchy is always inevitable in medicine. You are always going to have a staff, a fellow, a resident and a medical student. The staff is always going to be above the fellow who is always going to be above the resident, but the difference in power that is felt between those people in the hierarchy is very different in various systems. You can have a really flat hierarchy where everyone is closer to the same level, or you can have a very steep hierarchy where people find it very difficult to speak up to express their opinions in order to become part of shared decision making.

Over the course of our research, we learned that anesthesia trainees didn't do nearly as well at challenging authorities as we expected them to in a simulated environment. When put in a simulation where they were asked to do something that was clearly wrong, most residents acted by doing what was asked of them. In the first study, it was an ethical dilemma where, during an operation, the resident was asked by an authority to give blood to a Jehovah's Witness who had strictly refused any blood products. Despite having multiple opportunities to challenge the authority, the majority of anesthesia residents went on to give blood in the simulated environment $[1,2]$. We followed up from this with some qualitative work where we wanted to understand the simulated effect and whether trainees would actually act like this in real life. Interestingly enough, most of the trainees told us that they would have acted exactly that way in a real scenario. The reason for why they didn't want to speak up and challenge authority is actually very complex, however. This can have very harmful effects for patients when you are not using every member of your team and people aren't willing to engage in the decision making despite being perfectly able to do so, even as junior residents and medical students.

\section{WOULD YOU SAY THAT THIS HIERARCHY HAS BEEN GETTING BETTER OVER THE YEARS, OR HAS IT BEEN PRETTY STABLE?}

The good news is that the hierarchy has been getting better over the years. When we interview people who are relatively senior, they say things were not as progressive back in the day when they were junior, when it was acceptable to have behavior that was much more antisocial and hostile. I think a large part of this is creating a climate of psychological safety so that everyone in the team feels it is safe to speak up and be part of the shared decision making. That has been getting better. The bad news is that medicine is still very hierarchical and that hierarchy is still very strictly felt. People are afraid to speak up because it may have a negative impact on their career or evaluations. There are also a number of reasons that we find are well mirrored in the psychological, military and aviation literature, and even in areas of business and management. In healthcare, unfortunately, if you know something is wrong and you fail to speak up, it can have serious consequences for an individual patient.

CONSIDERING THAT THIS HIEARCHY CAN HAVE PROFOUND IMPLICATIONS, WHAT CHANGES NEED TO BE IMPLEMENTED TO GIVE MEDICAL TRAINEES THE OPPORUNITY TO SPEAK UP EVEN IF THAT MEANS DIRECTLY CONTRADICTING THEIR SUPERVISOR'S ORDERS?

We need to change the system. I think that we need to educate our trainees to give them the skills to speak up in a respectful manner, especially when they think things are not going the way they should. But it is not just about the trainees. We have to look at the whole system and get those at the top of the hierarchy to realize that, by creating a very inclusive leadership style, they can encourage people to get involved in decision making. This will increase the value they get from the whole team.

There are a lot of strategies that can be used for trainees to speak up. By bringing out this issue in the formal curriculum, people know it is an important skill. Teaching people that nobody wants a "yes man" or "yes person" is important. We want people who can contribute towards the team.

In terms of specific resources, we have tools from aviation and other industries to teach individuals to respectfully speak up, without feeling like what they are doing is going to get them into trouble. For example, we can use really simple things like the CUS (Concerned-Uncomfortable-Safety) tool, which comes from aviation. Using this approach, you start off by saying, "I am concerned about a decision." If that doesn't get the right result, you use the world uncomfortable. If that also doesn't achieve your goal, you follow up with safety. You say that you think it is a matter of patient safety. You say, "This patient will become harmed because of this decision." You escalate the way you say things in a respectful way. But this isn't just about making trainees competent to speak up. It is about a whole system. When you have unprofessional behaviors at work, you create a climate in which people are uncomfortable to speak up. That is not the responsibility of just the trainee; that is the responsibility of everyone, 
especially those at the top of the hierarchy. As a good leader, someone at the top of the hierarchy should make it very clear that they are interested in what you think as the medical student or resident. That is not just in a crisis situation, where it is needed the most, but also in all areas of patient care.

\section{CAN YOU TELL US ABOUT THE RESEARCH YOU ARE WORK- ING ON NOW?}

The research we are working on now involves teamwork simulation that we do at the University of Ottawa Skills and Simulation Centre. We do some quantitative research on how teams perform and how teams can work together. I also have a global health practice, so I have medical education work based around anesthesia and safe surgical care in low resource settings. Along the lines of what we have been talking about, we also have ongoing studies in hierarchy and how it affects team performance and education. What we are trying to do is open it up a bit more. Previously, we had been looking at anesthesia and respiratory therapy. Now we are trying to look at whole teams together. Because hierarchy happens within teams, it makes sense to interview people or do focus groups in a simulation where you have surgery together with anesthesia. In doing so, we can look at multiple perspectives, and we are hoping to get a more comprehensive view of this subject as a whole.

\section{WHAT ADVICE WOULD YOU OFFER ANY MEDICAL STUDENT OR RESIDENT WHO WISHES TO WORK IN MEDICAL EDUCA- TION?}

I think the best advice for medical students is as follows: if you really want to get involved in medical education research, it is best to make it programmatic. If you think about an area you are interested in, you don't try and answer everything in one study. You do a small study, which you build on to lead to another study. You have to do a program of research that slowly aims to build a bigger picture over time. I think it is very important to have that approach to research if you want to be successful. I think another thing that is needed in medical education research is a mentor. That is probably the most important thing. I have some great mentors here in Ottawa, and I think that really allows you to grow as a researcher through your career. The third thing that I would really recommend is to get some training. The days of people just doing a little bit of research at the side of their desk without any training and figuring things out on their own is over in medical education research as well as biomedical research. The entry level is now a master's degree or even in some areas a $\mathrm{PhD}$, and I really think that you need to get that formal university postgraduate training to pick up the research skills so that you can really build a career.

\section{JUST WANTED TO FOLLOW UP ON MENTORSHIP BECAUSE I SAW THAT YOU WERE DOING SOME WORK IN THAT AREA. WHAT VALUE DO YOU SEE IN HAVING A MENTOR AND HOW CAN THAT HELP A RESIDENT OR A MEDICAL STUDENT?}

I think the first thing to think about is that you really want more than one mentor. At any one time you may need multiple mentors, especially as you progress through your career. You might want somebody who is more of a clinical mentor in your specialty when you decide what you want to do as a medical student. You might also want somebody to mentor you in other aspects of your life, such as in research or quality improvement. The important thing to realize is that you might change over the course of your career. I personally have a great mentor Viren Naik who is currently the VP Education at The Ottawa Hospital. In Toronto, he was very much a research mentor for me while doing my fellowship. Now I do more research than he does, but he is still very much a mentor. It is just that he is more of a mentor in leadership and other skills. You have different mentors at different phases of your life. I think that the benefit is very much established in the literature. We recently published a literature review in the Canadian Journal of Anesthesia about mentorship in anesthesia, and found that you are more likely to have career success, especially in your academic career, if you have mentors [3]. This includes senior mentors and colleagues at the same stage as myself, which are both extremely valuable.

\section{ACKNOWLEDGEMENTS}

The author would like to thank Dr. Dylan Bould for taking his time to answer these questions and sharing his experiences and advice. The interview has been edited.

\section{REFERENCES}

1. Bould MD, Sutherland S, Sydor DT, et al. Residents' reluctance to challenge negative hierarchy in the operating room: a qualitative study. CJA. 2015;62(6):576-86.

2. Sydor DT, Bould MD, Naik VN, et al. Challenging authority during a life threatening crisis: the effect of operating theater hierarchy. BJA. 2013;110(3):46371.

3. Alisic S, Boet S, Sutherland S, Bould MD. A qualitative study exploring mentorship in anesthesiology: perspectives from both sides of the relationship. CJA. 2016;63(7):851-86. 